\section{RMD Open}

Rheumatic \&

Musculoskeletal Diseases

\title{
Reasons why osteoarthritis predicts mortality: path analysis within a Cox proportional hazards model
}

\author{
Ross Wilkie (1) , Simran Singh Parmar, ${ }^{2}$ Milica Blagojevic-Bucknall (D) , \\ Diane Smith, ${ }^{3}$ Martin J Thomas, ${ }^{1}$ Bethany Jane Seale, ${ }^{2}$ Gemma Mansell, ${ }^{4}$ \\ George Peat ${ }^{1}$
}

To cite: Wilkie R, Parmar SS, Blagojevic-Bucknall M, et al. Reasons why osteoarthritis predicts mortality: path analysis within a Cox proportional hazards model. RMD Open 2019;5:e001048. doi:10.1136/ rmdopen-2019-001048

Received 3 July 2019 Revised 23 October 2019 Accepted 23 October 2019

\section{Check for updates}

C Author(s) (or their employer(s)) 2019. Re-use permitted under CC BY-NC. No commercial re-use. See rights and permissions. Published by BMJ.

${ }^{1}$ Primary Care Centre Versus Arthritis, School of Primary, Community and Social Care, Keele University, Keele, UK ${ }^{2}$ Keele Medical School, Keele University, Keele, UK ${ }^{3}$ Manchester Metropolitan University, Manchester, UK ${ }^{4}$ Department of Psychology, Aston University, Birmingham, UK

\section{Correspondence to} Dr Ross Wilkie; r.wilkie@keele.ac.uk

\section{ABSTRACT}

Objectives To identify potentially modifiable factors that mediate the association between symptomatic osteoarthritis $(\mathrm{OA})$ and premature mortality. Methods A population-based prospective cohort study; primary care medical record data were linked to selfreport information collected by questionnaire in adults aged 50 years and over $(n=10415)$. OA was defined by primary care consultation and moderate-to-severe pain interference in daily life. A Cox proportional hazards analysis determined the total effect (TE) of OA on mortality after adjustment for potential confounders. Within the Cox model, path analysis was used to decompose the TE to assess the indirect and direct effects for selected potential mediators (anxiety, depression, unrefreshed sleep and walking frequency). Results are expressed as HRs with 95\% Cls derived from bootstrap resampling.

Results $O A$ was significantly associated with mortality (TE-adjusted HR 1.14; $95 \% \mathrm{Cl} 1.00$ to 1.29 ). The indirect effects for walking frequency were $1.05(95 \% \mathrm{Cl} 1.04$ to 1.06), depression 1.02 (95\% Cl 1.02 to 1.03$)$, anxiety 1.01 (95\% Cl 1.00 to 1.02) and unrefreshed sleep 1.01 (95\% Cl 1.00 to 1.01 ).

Conclusions The analysis indicates that encouraging people to walk and 'get out and about' in addition to targeting $\mathrm{OA}$ could be protective against excessive mortality. The findings also suggest that depression, anxiety and unrefreshed sleep have a role in premature mortality for people with $0 A$; however, this has low clinical significance.

\section{INTRODUCTION}

There is increasing interest in mortality as an outcome of osteoarthritis (OA) due to the sheer frequency and expected increase in the prevalence of the condition, and significant association with comorbidities, such as cardiovascular disease (CVD). ${ }^{1-3}$ Metaanalysis of studies examining the relationship between $\mathrm{OA}$ and mortality have highlighted conflicting results; however, this is due to differences in case and mortality definitions, selection of confounders and selection bias. ${ }^{4-6}$

\section{Key messages}

What is already known about this subject?

- Osteoarthritis (OA) is a serious disease; however, its relationship with mortality is unclear due to heterogeneity between studies and differences in approaches to the inclusion of covariates.

- While studies have adjusted for potential confounding and used regression modelling to highlight important covariates, they have not clearly identified the mechanisms that increase the risk of mortality in people with $0 \mathrm{~A}$, which will inform future management and preventative strategies.

What does this study add?

- The study uses a technique for mediation within a survival model to identify the pathways and modifiable targets to reduce mortality in people with $\mathrm{OA}$.

How might this impact on clinical practice?

- It highlights the need to focus on the impact, in addition to the condition itself, to reduce mortality in the large and growing number of people with $\mathrm{OA}$.

- Focusing on encouraging people to walk frequently or 'get out and about' is important for reducing mortality in people with $\mathrm{OA}$; while depression, anxiety and unrefreshed sleep appear to have a role, the clinical significance is low.

More recent reviews highlight a positive association between lower limb $\mathrm{OA}$ and cardiovascular mortality ${ }^{17}$; there have been reports of positive associations between radiographic knee OA and cause-specific mortality (CVD, diabetes and renal disease $),{ }^{8}$ symptomatic knee pain and cardiovascular mortality, ${ }^{9}$ and doctor-diagnosed OA with mortality linked to heart failure. ${ }^{10}$ Walking disability has been linked to the increased link between lower limb OA and mortality. ${ }^{411} 12$

Understanding links between OA and allcause mortality remains important to allow comparisons with other health conditions. Recent studies in the USA have highlighted 


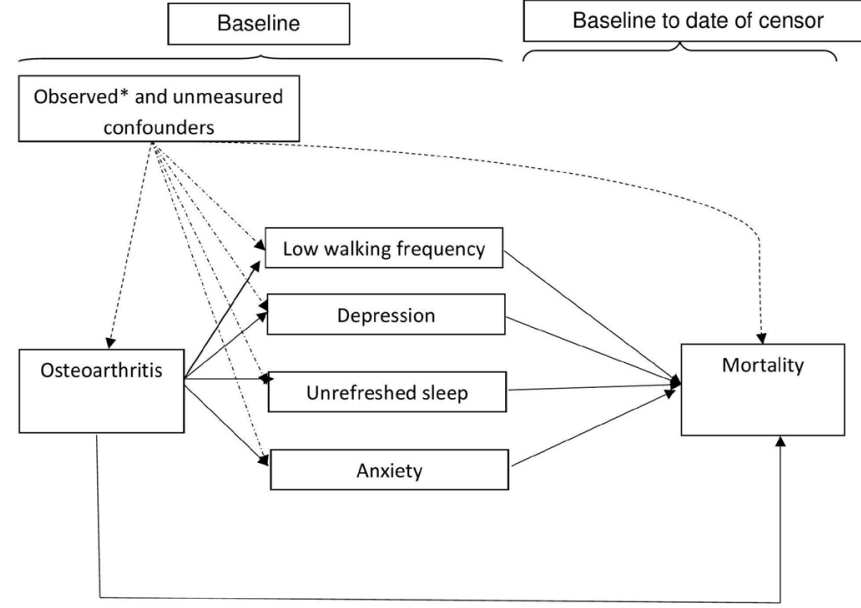

Direct effect of osteoarthritis on mortality

*Observed confounders were age, sex, education, occupation, smoking status, cognitive behaviour, $\mathrm{BMI}$, consultation for ischaemic heart disease, chronic obstructive pulmonary disease, diabetes, non-steroidal anti-inflammatories, self-report of heart conditions

Figure 1 Proposed pathways between osteoarthritis and mortality; direct and indirect effects through low walking frequency, depression, anxiety and unrefreshed sleep. BMI, body mass index.

a positive association between symptomatic lower limb OA and all-cause mortality. ${ }^{7}$ While studies have adjusted for potential confounding and used regression modelling to highlight important covariates, the mechanisms that increase the risk of all-cause mortality in people with OA, which will inform future management and preventative strategies, are under-researched. ${ }^{13-12}$ It is unclear whether the increased risk is due to the OA itself or to its impact which forms pathways to premature mortality. This paper builds on previous work to examine potential pathways that explain the link between OA and allcause mortality with the aim of identifying modifiable targets. ${ }^{13-15}$ Physical disability, which often follows lower limb OA, ${ }^{13}{ }^{14}$ has been identified as one mechanism that explains the increased risk of mortality, and is a target for healthcare. ${ }^{15}$ Infrequent walking and physical activity, which is associated with physical disability and premature mortality, ${ }^{16}$ may be a target that is relevant to all with $\mathrm{OA}$ (not only those with physical disability) and be part of self-management, optimal primary care and prevention of other comorbidities that may increase mortality risk, such as CVD and diabetes. ${ }^{17}$ The analysis also explores the role of mood (anxiety and depression) and unrefreshed sleep; it is possible that OA increases anxiety, depression and unrefreshed sleep which leads to premature mortality (figure 1). ${ }^{18-21}$ Mediation analysis is used to investigate pathways, although this has rarely been undertaken using survival analysis due to the challenge of accounting for time. The aim of this study was to examine potential mechanisms of the impact of OA on all-cause mortality, based on a novel technique for mediation analysis within a survival model. Specifically, the study tests the hypotheses that premature mortality is associated with symptomatic $\mathrm{OA}$ and is mediated through walking frequency, depression, anxiety and unrefreshed sleep.

\section{METHODS}

\section{Design, study setting and population}

The North Staffordshire Osteoarthritis Project (NorStOP) is a population-based prospective cohort study. ${ }^{22}$ The sampling frame comprised individuals aged 50 years and over who were registered to receive care from one of six general practices in North Staffordshire, UK, gave written consent for medical record review and were mailed a baseline questionnaire, between April 2002 and May 2003, which collected data on health and sociodemographic factors. In the UK, general practice registers offer a convenient sampling frame for populationbased studies; an estimated $98 \%$ of the UK residents are registered. Reminders were sent to non-responders 2 and 4 weeks after the initial mailing.

Of 10432 potential participants who gave consent to medical record review, OA status could be determined for all; however, $17(0.16 \%)$ had missing data on vital status (figure 2); this figure was deemed negligible and these 17 participants were removed from the analysis. Of the remaining 10415 participants, 2233 (21.4\%) did not have complete data on mediators and confounders; participants with incomplete data were on average significantly older and more likely to be female. To obtain data for the primary analyses, multiple imputation by chained equations was used to impute missing data ${ }^{23}$ in Stata V.13. All confounders, mediators and outcome were used in the multiple imputation model; logit regression models were specified for binary variables and one skewed continuous variable (cognitive behaviour) was normalised prior to imputation, and transformed back to its original scale afterwards. The two-stage calculation was used to determine the number of required imputations, which was $32 .^{24}$

\section{Identification of $\mathrm{OA}$}

A combination of medical record and questionnaire data was used to identify symptomatic OA ${ }^{25}$ General practitioners in the study used the hierarchical Read code system to code the reasons for clinical encounters in primary care consultations. ${ }^{26}$ Morbidity data (ie, symptoms and diseases) in this system are grouped under 19 main Read chapters. Data collected at the second hierarchical level or above were used to identify diagnostic groups. Individuals were defined as having OA if they had consulted general practice for OA between 2000 and 2008 based on Read code N05., and indicated moderate-to-severe pain interference on daily life in the Medical Outcomes Short Form 36 at baseline. ${ }^{27}$ As OA is a long-standing, often progressive chronic condition, it was assumed that a clinician-established diagnosis at any point during the study period implied that OA was likely present at least to some degree during the entire period of observation. 


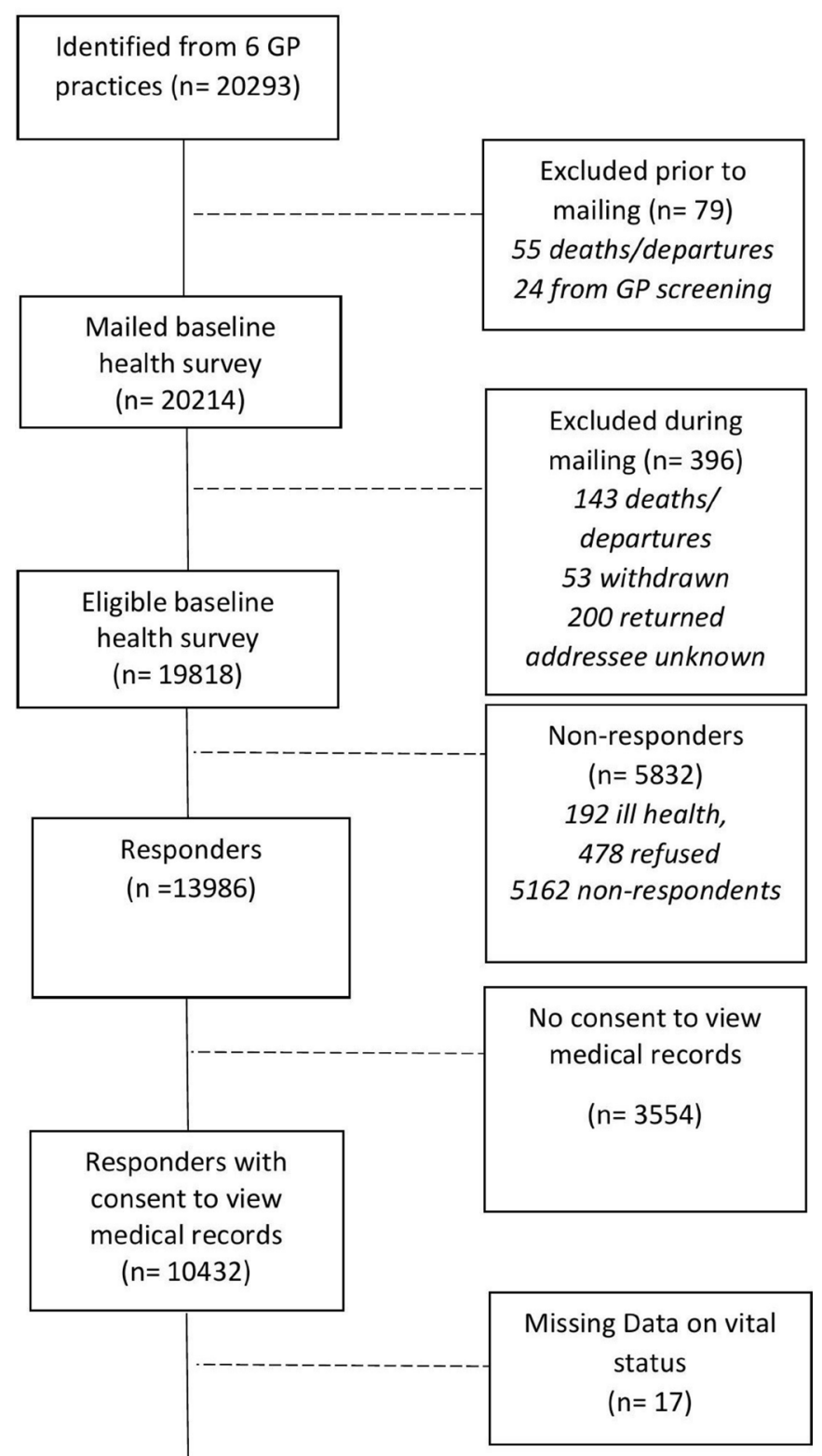

Number for analysis

$(n=10415)$

Figure 2 Flow of study participants. GP, general practitioner.

\section{Outcome}

Vital status was obtained from the patient registration system held at the local primary care trust and from dates notified to the NorStOP project team. These later dates of death were confirmed using manual tracing of the National Health Service Summary Care Record Demographic system. The outcome of interest was time to death, and was taken as time from the date of baseline questionnaire completion to the date of death or censoring took place. Information on vital status was available until 01 October 2012 and this is the censor date for those who survived.

\section{Proposed mediators}

The technique to perform mediation analysis required all mediators to be binary. ${ }^{28-30}$ Depression and anxiety were measured using the Hospital Anxiety and Depression Scale. Raw scores were categorised as no depression/ anxiety (0-7) or depression/anxiety (possible/probable cases; 8-21). ${ }^{31}$ Walking frequency was measured using a single item ('Thinking about the past 4 weeks, how often do you go out for a walk? All/most/some/few/no days'). Using the median value, participants indicating all/most/some days were considered as frequent walkers (high frequency) and few/no days were considered as infrequent walkers (low frequency). ${ }^{22}$ One item from the Estimation of Sleep Problems Scale was used to identify unrefreshed sleep. ${ }^{32}$ Participants indicating that they experienced difficulties in the non-restorative sleep item ('During the past 4 weeks, did you wake up after your usual amount of sleep feeling tired and worn out?') on most nights in the past 4 weeks were classified as having unrefreshed sleep and compared with those who experienced no difficulties on some nights. ${ }^{33}$

\section{Confounders}

Comorbidities, sociodemographic and lifestyle factors associated with $\mathrm{OA}$ and morbidity were included as confounders. ${ }^{13-14}$ Medical records were used to identify ischaemic heart disease, chronic obstructive pulmonary disease and diabetes in the same manner as for OA (ie, primary care consultation between 2000 and 2008). Number of prescriptions for non-steroidal antiinflammatory drugs were also captured during the same period, dichotomised at zero, which was the median number of prescriptions. To cover all CVD, we included self-reported measures and asked responders to indicate if they had 'heart problems' or 'raised blood pressure'. Age, gender, educational attainment, occupational socioeconomic status, smoking status and cognitive impairment were all reported by questionnaire. Educational attainment (finished education on leaving school; gone onto full-time education including college or university) was included as a proxy measure of lifetime socioeconomic status. Participants' current or most recent job was categorised to non-manual or manual. ${ }^{34}$ Self-report of current smoking status was categorised to current versus non-smoker. Cognitive impairment was measured using the cognitive and alertness behaviour subscale of the Functional Limitations Profile; scores range from 0 to $100 .^{35}$ Body mass index (BMI) was calculated from participants reported height and weight.

\section{Statistical analysis}

Cox proportional hazard modelling was used to obtain associations between $\mathrm{OA}$ and time to death, presented as HRs with $95 \%$ CIs. First, unadjusted associations were obtained, followed by adjustment for all confounders. The proportionality of the hazards assumption was assessed via likelihood-ratio test comparing a model including time-dependent constructs of all confounders to a smaller model including time-fixed constructs only. 
Censoring was assumed non-informative and was taken as the earliest of withdrawal from the study/departure from practice or 01 October 2012.

The technique to perform mediation analysis within survival analysis was based on a counterfactual framework. ${ }^{28}{ }^{29}$ Within the counterfactual framework, each participant is observed under one set of circumstances and then consideration is given to what would have happened under counterfactual circumstances. This involves replication of analyses, where in the first instance, the exposure takes the original value and in the replication, it takes the opposite or counterfactual value. Weights are derived from logistic regression of the binary mediator on the exposure and confounders. ${ }^{29}$ When the assumptions of proportional hazards and non-informative censoring are met, the weighted Cox regression model will give HRs which are estimates of the indirect and direct effects; the indirect effect is the 'amount' of mediation and the extent to which each proposed mediator explains the link between $\mathrm{OA}$ and mortality, while the direct effect is the extent of the remaining link between $\mathrm{OA}$ and mortality once the indirect effect of the proposed mediator is accounted for. The product of these two HRs provides the HR for the total effect (TE) (ie, the overall association between OA and mortality). CIs were calculated using bootstrapping to account for the non-normal distribution of the. ${ }^{29}$ This analysis was performed using code developed for the statistical package $\mathrm{R}^{29}{ }^{30}$

First, associations between $\mathrm{OA}$ and each mediating variable were examined using logistic regression; all associations between $\mathrm{OA}$ and potential mediators were adjusted for potential confounders and are presented as ORs with 95\% CIs. Results of the mediation analyses (carried out using the described technique) are presented as HRs for the direct, indirect and total effects with associated bootstrapped $95 \%$ CIs. Mediation was indicated by the presence of a significant indirect effect. The descriptive analysis was performed using Stata V.13 and the survival and mediation analyses were carried out using R.

\section{Sensitivity analyses}

Sensitivity of the findings from the primary analyses was assessed when only those participants with complete mediator and confounder data were used $(n=8182)$. Sensitivity analysis was performed to assess the robustness of findings to potential unmeasured confounding, using the $\mathrm{E}$ value approach introduced by VanderWeele and Ding ${ }^{36}$; E value represents the minimal needed association between a confounder and both the outcome and exposure to fully explain observed associations.

\section{RESULTS}

\section{Cohort characteristics}

Of the 10415 participants, $3172(30.5 \%)$ of the sample had OA (table 1 ). The mean age was 66.2 years (SD 10.2 years) and $53.8 \%$ were female. The median time from the date of questionnaire return to death among those who died (1643 (15.8\%)) was 2076 days (range 1-3807). Table 1 also gives detail on completeness for each of the patient characteristics.

\section{Relationship between $\mathrm{OA}$ and mortality}

Of those with OA, 606 (19.0\%) died during the study period, compared with 1039 (14.3\%) who didn't have $\mathrm{OA}$; median person-time (IQR) of follow-up was 3674 days (3461-3835) cf. 3646 days (3472-3834). Figure 3 shows survival function plots over 10 years for those with and without OA. Incidence mortality rate per 1000 personyears was 1.06 among those with $\mathrm{OA}$ and 1.04 among those without, with unadjusted HR 1.30 (95\% CI 1.22 to 2.30). The association between $\mathrm{OA}$ and time to death was attenuated when adjusted for confounders; adjusted HR was 1.11 (95\% CI 1.06 to 1.17). E value associated with the estimate was 1.36 (and 1.25 for the lower CI); this is the association that an unmeasured confounder would have to have with both OA and mortality, conditional on measured confounders, to fully explain the observed association. The likelihood-ratio test did not reveal a significant difference between models with and without time-dependent constructs of confounders $\left(\chi^{2}=11.79, \mathrm{p}\right.$ value $=0.1078)$; it is plausible to assume that proportionality of hazards assumption was satisfied.

\section{Mediation of association between $\mathrm{OA}$ and mortality}

OA was positively associated with all of the proposed mediators (table 2). Corresponding $\mathrm{E}$ values are also given in table 2. The adjusted indirect effects for low walking frequency were 1.05 (95\% CI 1.04 to 1.06 ), depression 1.02 (95\% CI 1.02 to 1.03), unrefreshed sleep 1.01 (95\% CI 1.00 to 1.01 ) and anxiety 1.01 (95\% CI 1.00 to 1.02 ). Notable attenuation in the direct effects occurred when walking frequency was included as a mediator $(1.05$ (95\% CI 1.00 to 1.10)). Direct effects for depression, anxiety and unrefreshed sleep were 1.08 (95\% CI 1.03 to 1.13), 1.10 (95\% CI 1.05 to 1.015 ) and 1.09 (95\% CI 1.05 to $1.14)$, respectively.

When analyses were restricted to only those with complete mediator and confounder data $(n=8182)$, the findings were generally similar; however, analyses based on imputed data gave estimates which were closer to the null, and more precise (table 3 ).

\section{DISCUSSION}

This study examined potential mechanisms between $\mathrm{OA}$ and all-cause mortality within a survival model with the aim of identifying potentially modifiable targets for healthcare. ${ }^{29}$ The findings indicate a positive association between symptomatic $\mathrm{OA}$ and all-cause mortality and highlight frequent walking as a potential target to reduce all-cause mortality. While anxiety, depression and unrefreshed sleep had statistically significant effects, the extent of their mediation effect has low clinical significance.

While the HRs in the analysis can be considered to be low (adjusted HR 1.11 (95\% CI 1.06 to 1.17) following 
Table 1 Characteristics of the study participants (10415 participants)

\begin{tabular}{|c|c|c|c|}
\hline \multirow[b]{2}{*}{ Variable } & & \multirow{2}{*}{$\begin{array}{l}\text { No osteoarthritis } \\
n=7243(69.5 \%)\end{array}$} & \multirow{2}{*}{$\begin{array}{l}\text { Osteoarthritis } \\
\mathrm{n}=3172(30.5 \%)\end{array}$} \\
\hline & & & \\
\hline \multirow[t]{2}{*}{ Death } & No & $6204(86)$ & $2568(81)$ \\
\hline & Yes & $1039(14)$ & $604(19)$ \\
\hline Age, years & Mean (SD) & $65.3(10.1)$ & $68.0(10.1)$ \\
\hline \multirow[t]{2}{*}{ Sex } & Male & 3525 (49) & $1284(40)$ \\
\hline & Female & $3718(51)$ & $1888(60)$ \\
\hline \multirow[t]{3}{*}{ Further education } & No & $6158(85)$ & $2813(89)$ \\
\hline & Yes & $930(13)$ & $269(8)$ \\
\hline & Missing & $155(2)$ & $90(3)$ \\
\hline \multirow[t]{3}{*}{ Occupational class } & Non-manual & $3141(43)$ & $1141(36)$ \\
\hline & Manual & $3624(50)$ & $1726(54)$ \\
\hline & Missing & $478(7)$ & $305(10)$ \\
\hline \multirow[t]{3}{*}{ Smoking } & No/previous & $4176(58)$ & $1887(60)$ \\
\hline & Current & $3003(41)$ & $1245(39)$ \\
\hline & Missing & $64(1)$ & $40(1)$ \\
\hline Cognitive behaviour $(0-100)^{*}$ & Median (IQR) & $0(0-13.2)$ & $12.7(0-37.2)$ \\
\hline \multirow[t]{2}{*}{ IHD consultation $†$} & No & $6760(93)$ & $2749(87)$ \\
\hline & Yes & $483(7)$ & $423(13)$ \\
\hline \multirow[t]{2}{*}{ COPD consultation $†$} & No & $6972(96)$ & 2969 (94) \\
\hline & Yes & $271(4)$ & $203(6)$ \\
\hline \multirow[t]{2}{*}{ Diabetes consultation $†$} & No & $6894(95)$ & $2897(91)$ \\
\hline & Yes & $349(5)$ & $275(9)$ \\
\hline \multirow[t]{2}{*}{ NSAIDs prescription† } & No & $5072(70)$ & $1488(47)$ \\
\hline & Yes & $2171(30)$ & $1684(53)$ \\
\hline \multirow[t]{2}{*}{ Self-report heart condition } & No & 4475 (62) & 1507 (48) \\
\hline & Yes & $2768(38)$ & $1665(52)$ \\
\hline Body mass index $\neq, \mathrm{kg} / \mathrm{m}^{2}$ & Mean (SD) & $26.2(4.4)$ & $27.7(5.2)$ \\
\hline \multirow[t]{3}{*}{ Walking frequency } & High & $4257(59)$ & $1129(36)$ \\
\hline & Low & 2798 (39) & $1974(62)$ \\
\hline & Missing & $188(2)$ & $69(2)$ \\
\hline \multirow[t]{3}{*}{ Depression } & Non-case & $5970(83)$ & $1947(61)$ \\
\hline & Possible/probable case & $1106(15)$ & $1143(36)$ \\
\hline & Missing & $167(2)$ & $82(3)$ \\
\hline \multirow[t]{3}{*}{ Anxiety } & Non-case & $4785(66)$ & $1375(43)$ \\
\hline & Possible/probable case & $2284(32)$ & $1719(54)$ \\
\hline & Missing & $174(2)$ & $87(3)$ \\
\hline \multirow[t]{3}{*}{ Unrefreshed sleep } & No & $6125(85)$ & 2191 (69) \\
\hline & Yes & $907(12)$ & $900(28)$ \\
\hline & Missing & $211(3)$ & $81(3)$ \\
\hline
\end{tabular}

All values are $\mathrm{N}(\%)$ unless otherwise stated.

*Higher score indicates worse score; based on 6833 and 2940 participants for those without and with OA, respectively. †Obtained from medical records.

¥Based on 6955 and 3024 participants for those without and with OA, respectively.

COPD, chronic obstructive pulmonary disease; IHD, ischaemic heart disease; NSAIDs, non-steroidal anti-inflammatory drugs. 


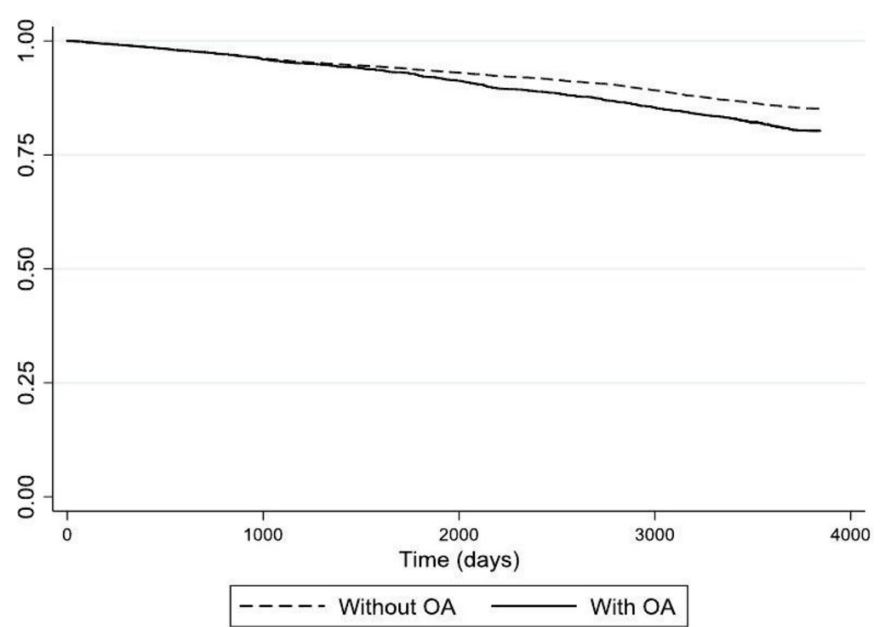

Figure 3 Survival probability over 10 years for those with and without osteoarthritis (OA).

adjustment for other key confounders, the increased link of mortality is applicable to a large number of people in the general population who have symptomatic OA. Walking frequency explained the greatest amount of the link between OA and premature mortality (indirect effect 1.05 (95\% CI 1.04 to 1.06) cf. TE 1.10 (95\% CI 1.05 to 1.15)). The extent of the indirect effect was comparable to that for physical function, measured via speed of walking, on the link between radiographic hip OA and
CVD mortality. This finding also links with previous work which has indicated that walking disability is associated with premature mortality in older adults with $\mathrm{OA},{ }^{781115}$ as walking disability leads to reduced walking frequency. ${ }^{3}$ However, of the low-frequency walkers with OA, more than one in five $(22.7 \%)$, one in three $(34.6 \%)$ and two of three $(65.0 \%)$ had little or no limitation walking more than one mile, half a mile or 100 yards, respectively, indicating that limitation is not always the barrier to frequent walking. Encouraging people to maintain levels of walking and physical activity and targeting a reduction in physical limitation in clinical practice to allow this is important. Low walking frequency is linked with a number of anatomical (eg, muscle weakness) and physiological impairments (eg, hypercholesterolaemia and hypertension) which leads to comorbidity, such as CVD and diabetes, which are associated with premature mortality. ${ }^{37}$ Small amounts of regular walking and getting out and about can offer protection against comorbidity, including depression and CVD. ${ }^{38}$

While the indirect effects of depression, anxiety and unrefreshed sleep can be considered as statistically significant, the level of clinical significance is debatable. In this analysis, $18.2 \%, 9.1 \%$ and $8.3 \%$ of the increased risk of all-cause mortality in people with OA were explained by depression, anxiety and unrefreshed sleep, respectively; although the adjusted association between $\mathrm{OA}$ and

Table 2 Pathways between osteoarthritis and mortality via walking frequency, depression, anxiety and unrefreshed sleep: total, direct and indirect effects

\begin{tabular}{|c|c|c|c|}
\hline \multirow[b]{2}{*}{ Mediator } & \multicolumn{2}{|l|}{$\begin{array}{l}\text { Association between } \\
\text { osteoarthritis and } \\
\text { potential mediator }\end{array}$} & \multirow[b]{2}{*}{ Adjusted HR $(95 \% \mathrm{Cl})$} \\
\hline & Adjusted OR $(95 \% \mathrm{Cl})$ & Pathway & \\
\hline & - & Total effect (no mediators) & $1.11(1.06$ to 1.17$)$ \\
\hline Walking frequency & & Direct & 1.05 (1.00 to 1.10$)$ \\
\hline Frequent walker & Reference & Indirect & 1.05 (1.04 to 1.06$)$ \\
\hline Non-frequent walker & $1.89(1.82 \text { to } 1.97)^{\star}$ & Total & $1.10(1.05$ to 1.15$)$ \\
\hline Depression & & Direct & 1.08 (1.03 to 1.13$)$ \\
\hline No depression & Reference & Indirect & $1.02(1.02$ to 1.03$)$ \\
\hline Depression & $2.10(2.00$ to 2.21$) \dagger$ & Total & $1.11(1.06$ to 1.16$)$ \\
\hline Anxiety & & Direct & 1.10 (1.05 to 1.15$)$ \\
\hline No anxiety & Reference & Indirect & $1.01(1.00$ to 1.02$)$ \\
\hline Anxiety & $1.96(1.88$ to 2.05$) \ddagger$ & Total & $1.11(1.06$ to 1.16$)$ \\
\hline Unrefreshed sleep & & Direct & 1.09 (1.05 to 1.14$)$ \\
\hline Refreshed sleep & Reference & Indirect & $1.01(1.00$ to 1.01$)$ \\
\hline Unrefreshed sleep & $1.98(1.88$ to 2.09$) \S$ & Total & 1.12 (1.08 to 1.17$)$ \\
\hline
\end{tabular}

All models adjusted for age, sex, education, occupation, smoking status, cognitive behaviour, BMI, consultation for ischaemic heart disease, chronic obstructive pulmonary disease, diabetes, non-steroidal anti-inflammatories and self-report of heart conditions.

Significant associations between predictor and mediator and indirect effects are in bold.

${ }^{*} \mathrm{E}$ value for point estimate=2.09; $\mathrm{E}$ value for lower $\mathrm{Cl}=2.04$.

$\dagger E$ value for point estimate=2.26; $\mathrm{E}$ value for lower $\mathrm{Cl}=2.18$.

$\ddagger E$ value for point estimate=2.15; $\mathrm{E}$ value for lower $\mathrm{Cl}=2.08$.

$\S E$ value for point estimate=2.16; $\mathrm{E}$ value for lower $\mathrm{Cl}=2.08$.

BMI, body mass index. 
Table 3 Sensitivity analysis in complete cases $(n=8182)$; pathways between osteoarthritis and mortality via walking frequency, depression, anxiety and unrefreshed sleep: total, direct and indirect effects

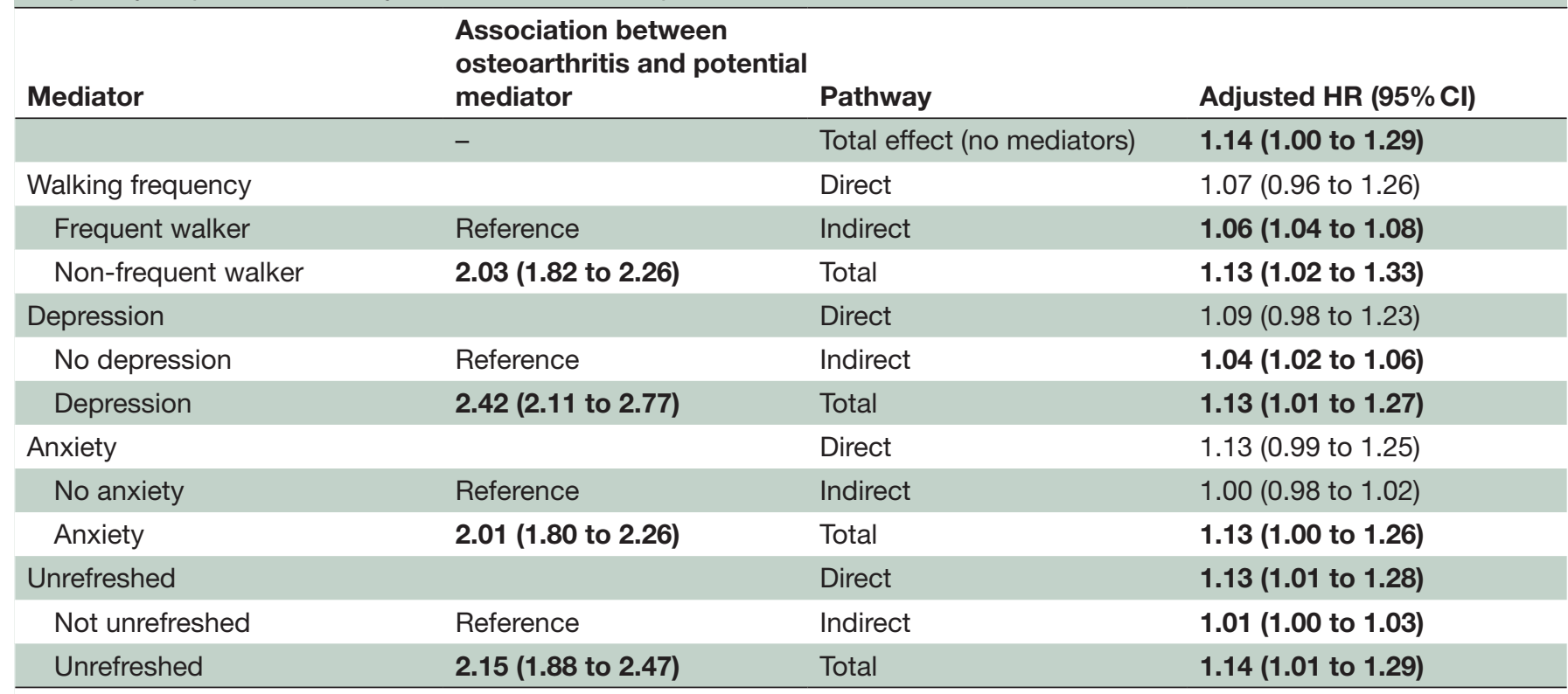

All models adjusted for age, sex, education, occupation, smoking status, cognitive behaviour, BMI, consultation for ischaemic heart disease, chronic obstructive pulmonary disease, diabetes, non-steroidal anti-inflammatories and self-report of heart conditions.

Significant associations between predictor and mediator and indirect effects are in bold.

BMI, body mass index.

all-cause mortality is also low (ie, HR 1.14). The role of depression, anxiety and unrefreshed sleep on mortality is often unclear due to confounding from comorbidity and sociodemographic and lifestyle factors, ${ }^{39}$ although in these analyses, all three continued to explain, even if small, a role in people with OA. While links with physical function may explain part of the mechanism for unrefreshed sleep, anxiety and depression, further research is required to further clarify these pathways. The selection of confounders in studies of OA and mortality prompts debate over the role of covariates. Obesity was included in this study as a confounder, while in other studies, it has been highlighted as having a role in mortality for people with knee OA. ${ }^{178}$ In additional analysis, in this study, obesity exerted no significant mediating effect on the pathway between OA and mortality (indirect effect 1.00 (95\% CI 0.98 to 1.01$)$ ).

The study has a number of strengths. A clinical definition of OA, which captured the presence of symptomatic $\mathrm{OA}$, was used and mortality data were obtained from a national data source. ${ }^{25}$ The diagnoses of $\mathrm{OA}$ in medical records was dependent on clinicians' approaches to identifying OA and is based on a range of factors linked to the clinical syndrome and may include radiographic signs; this may lead to misclassification of OA. High rates of sensitivity $\left(82 \%^{40}\right)$ and specificity $\left(100 \%^{41}\right)$ have been reported for OA identified via medical records but these estimates are dependent on the reference standard selected. The diagnoses of $\mathrm{OA}$ in medical record may also underestimate the diagnoses of hand $\mathrm{OA}$ and it is expected that there will only be a small number of people classified as having $\mathrm{OA}$ who have only hand $\mathrm{OA}^{42}$; the majority of those with OA in this study will have lower limb OA.

This study was a large, population-based study sampled from the general population. The response rate was high and was comparable to other population-based studies that have used postal questionnaires. The available data covered important mediators and confounders of the relationship between OA and mortality. ${ }^{13-15}$ Limitations of the data were that joint-specific OA was not coded in the electronic health record data and cause-specific mortality could not be identified; this prevented analysis of the relationship with mortality with lower limb OA and a focus on CVD which has been identified as the cause of mortality most pertinent for OA. ${ }^{78}$ Self-reported data was included; while this self-report data can be limited by inaccuracies, through recall bias or misinterpretation of questions, it is the most appropriate method to collect data on the impact of OA. Validated questionnaires were used to capture these constructs. ${ }^{22} 2732$ To adjust for potential misclassification of BMI due to discrepancies in selfreported height and weight, the analysis was adjusted for sociodemographic factors, including age, gender, education and occupational status, resulting in a close approximation of actual BMI. ${ }^{43} 44$ The severity of OA could not be identified in this data and maybe a confounder of the relationship between $\mathrm{OA}$ and mortality and impact on the estimates of the indirect and direct effects when mediators were examined. In addition, there may be other confounders that are significant but were not included in this study. Sensitivity analysis indicated that unmeasured confounders would need to have a moderate association with $\mathrm{OA}$ and mortality in addition to the factors 
already included to impact on the estimates. The need for binary variables for this analysis may result in the loss of precision and misclassification. ${ }^{45} 46$ This also prevented examination for trends in the extent of mediation with increasing levels of exposures. ${ }^{46}$

The study is longitudinal in nature; however, OA and the mediating and confounding factors were measured at the same time point. While modelling the relationship and pathways between OA and mortality is challenging, the method used in this analysis is currently the best approach to understanding the complex relationship. ${ }^{47}$ Although the causal inferences indicated by this analysis should be interpreted with caution, the findings provide empirical support for the proposed theoretical mechanism and targets for interventions. ${ }^{29} 47$ The analytical method used is limited to including one binary mediator at a time. This may underestimate the effect of potential mediators and also prevents further exploration of the complex relationship, for example, identifying reasons for the mediating effect of depression and unrefreshed sleep, and the further role of comorbidity. Consideration of multiple hypotheses simultaneously increased the likelihood of a type 1 error $^{48}$ and it was not possible to correct for this here.

This study suggests that further research on understanding the link with mortality should focus on clinical/ symptomatic OA. The potential to examine for mediation and test pathways within Cox proportional models indicate a need to move away from adjusted regression models to identify targets for interventions to reduce mortality linked to OA. Further development of statistical models is required to further understand the complex relationship between $\mathrm{OA}$ and mortality.

In conclusion, the findings of the study indicate the significant relationship between symptomatic OA and mortality. The common occurrence of $\mathrm{OA}$ in the general population indicate clinical and population approaches to reduce the impact and reduce mortality. This approach to understanding the pathway from OA to mortality indicates that walking frequency is a key target to reduce mortality; small amounts of frequent walking and getting out and about could reduce the extent of premature mortality in people with $\mathrm{OA}$. The mediating effect of depression, anxiety and unrefreshed sleep was of low clinical significance.

Contributors All the authors contributed substantially to (i) the conception and design of the study, acquisition of data, and analysis and interpretation of data, (ii) drafting of this manuscript and have given final approval of this version for publication.

Funding This study is supported financially by a programme grant awarded by the Medical Research Council, UK (grant code: G9900220), and by funding secured from the North Staffordshire Primary Care R\&D Consortium for NHS service support costs. MJT is supported by an Integrated Clinical Academic Programme Clinical Lectureship from the National Institute for Health Research (NIHR) and the Health Education England (HEE) (ICA-CL-2016-02-014).

Disclaimer The views expressed in this publication are those of the authors and not necessarily those of the NHS, the NIHR, the HEE or the Department of Health and Social Care.

Competing interests None declared.
Patient and public involvement statement Keele's experienced primary care Research User Group has 75 members in 67 projects in all the stages of research. For this proposed body of research, we have actively listened to users' experiences of the impact of osteoarthritis and the reasons for this. The need for dynamic approaches to care and for treatments that reduce symptoms and low priority given to musculoskeletal problems were recurrent findings.

Patient consent for publication Not required.

Ethics approval The North Staffordshire Local Research Ethics Committee approved this study (REC reference numbers: 1351, 1430 and 05/Q2604/20).

Provenance and peer review Not commissioned; externally peer reviewed.

Data availability statement Data are available on reasonable request.

Open access This is an open access article distributed in accordance with the Creative Commons Attribution Non Commercial (CC BY-NC 4.0) license, which permits others to distribute, remix, adapt, build upon this work non-commercially, and license their derivative works on different terms, provided the original work is properly cited, appropriate credit is given, any changes made indicated, and the use is non-commercial. See: http://creativecommons.org/licenses/by-nc/4.0/.

ORCID iDs

Ross Wilkie http://orcid.org/0000-0003-4825-714X

Milica Blagojevic-Bucknall http://orcid.org/0000-0001-7230-7771

\section{REFERENCES}

1. Cleveland RJ, Callahan LF. Can osteoarthritis predict mortality? NC Med J 2017;78:322-5.

2. Kassebaum NJ, Arora M, Barber RM, et al. Global, regional, and national disability-adjusted life-years (DALYs) for 315 diseases and injuries and healthy life expectancy (HALE), 1990-2015: a systematic analysis for the global burden of disease study 2015. Lancet 2016;388:1603-58.

3. Hawker GA, Croxford R, Bierman AS, et al. All-Cause mortality and serious cardiovascular events in people with hip and knee osteoarthritis: a population based cohort study. PLoS One 2014;9:e91286.

4. Veronese N, Cereda E, Maggi S, et al. Osteoarthritis and mortality: a prospective cohort study and systematic review with meta-analysis. Semin Arthritis Rheum 2016;46:160-7.

5. Han XZ, Liu Z, Kong LD, et al. Association between osteoarthritis and mortality: a meta-analysis. Int J Clin and Exp Med 2017;10:1094-100

6. Xing $D, X u Y$, Liu $Q$, et al. Osteoarthritis and all-cause mortality in worldwide populations: grading the evidence from a meta-analysis. Sci Rep 2016;6:24393.

7. Osteoarthritis: A Serious Disease. Submitted to the U.S. Food and drug administration December 1, 2016 [Internet]. Osteoarthritis Research Society International, 2016. Available: http://www.oarsi. org/sites/default/files/docs/2016/oarsi_white_paper_oa_serious_ disease_121416_1.pdf [Accessed 18th Aug 2019].

8. Mendy A, Park J, Vieira ER. Osteoarthritis and risk of mortality in the USA: a population-based cohort study. Int J Epidemiol 2018;47:1821-9.

9. Cleveland RJ, Alvarez C, Schwartz TA, et al. The impact of painful knee osteoarthritis on mortality: a community-based cohort study with over 24 years of follow-up. Osteoarthritis and Cartilage 2019;27:593-602.

10. Turkiewicz A, Neogi T, Björk J, et al. All-Cause mortality in knee and hip osteoarthritis and rheumatoid arthritis. Epidemiology 2016;27:479-85.

11. Nüesch E, Dieppe P, Reichenbach $\mathrm{S}$, et al. All cause and disease specific mortality in patients with knee or hip osteoarthritis: population based cohort study. BMJ 2011;342:d1165.

12. Kluzek S, Sanchez-Santos MT, Leyland KM, et al. Painful knee but not hand osteoarthritis is an independent predictor of mortality over 23 years follow-up of a population-based cohort of middle-aged women. Ann Rheum Dis 2016;75:1749-56.

13. King LK, Kendzerska T, Waugh EJ, et al. Impact of osteoarthritis on difficulty walking: a population-based study. Arthritis Care Res 2018;70:71-9.

14. Song J, Chang AH, Chang RW, et al. Relationship of knee pain to time in moderate and light physical activities: data from osteoarthritis initiative. Semin Arthritis Rheum 2018;47:683-8.

15. Barbour KE, Lui L-Y, Nevitt MC, et al. Hip osteoarthritis and the risk of all-cause and disease-specific mortality in older women: a population-based cohort study. Arthritis Rheumatol 2015;67:1798-805. 
16. Mok A, Khaw K-T, Luben R, et al. Physical activity trajectories and mortality: population based cohort study. BMJ 2019;80.

17. Hay E, Dziedzic K, Bartlam B, et al. Optimal primary care management of clinical osteoarthritis and joint pain in older people: a mixed-methods programme of systematic reviews, observational and qualitative studies, and randomised controlled trials. Southampton (UK): NIHR Journals Library, 2018.

18. Bennell KL, Hunter DJ, Hinman RS. Management of osteoarthritis of the knee. BMJ 2012;345:e4934.

19. Wise BL, Niu J, Zhang Y, et al. Psychological factors and their relation to osteoarthritis pain. Osteoarthritis Cartilage 2010;18:883-7.

20. Liu Q, Niu J, Li H, et al. Knee symptomatic osteoarthritis, walking disability, NSAIDs use and all-cause mortality: population-based Wuchuan osteoarthritis study. Sci Rep 2017;7:3309.

21. Neogi T. The epidemiology and impact of pain in osteoarthritis. Osteoarthritis Cartil 2013;21:1145-53.

22. Thomas E, Wilkie R, Peat G, et al. The North Staffordshire osteoarthritis project - NorStOP: prospective, 3-year study of the epidemiology and management of clinical osteoarthritis in a general population of older adults. BMC Musculoskelet Disord 2004;5:2.

23. White IR, Royston P, Wood AM. Multiple imputation using chained equations: issues and guidance for practice. Stat Med 2011;30:377-99.

24. von Hippel PT. How many imputations do you need? A two-stage calculation using a quadratic rule. Sociol Methods Res 2018

25. Felson DT. Identifying different osteoarthritis phenotypes through epidemiology. Osteoarthritis Cartilage 2010;18:601-4.

26. NHS Information. The clinical terms version 3 the read codes. Birmingham: NHS Information Authority, 2000.

27. Ware JE, Sherbourne CD. The mos 36-item short-form health survey (SF-36). I. conceptual framework and item selection. Med Care 1992;30:473-83.

28. Lange T, Vansteelandt S, Bekaert M. A simple unified approach for estimating natural direct and indirect effects. Am J Epidemiol 2012;176:190-5.

29. Rochon J, du Bois A, Lange T. Mediation analysis of the relationship between institutional research activity and patient survival. $B M C$ Med Res Methodol 2014;14.

30. Smith D. A study of pain and mortality: the role of lifestyle, health, social and psychological factors. Keele University, Keele, 2016 Available: http://eprints.keele.ac.uk/2415/1/SmithDPhD2016.pdf

31. Zigmond AS, Snaith RP. The hospital anxiety and depression scale. Acta Psychiatr Scand 1983;67:361-70.

32. Jenkins CD, Stanton B-A, Niemcryk SJ, et al. A scale for the estimation of sleep problems in clinical research. $J$ Clin Epidemiol 1988;41:313-21.
33. Tang NKY, McBeth J, Jordan KP, et al. Impact of musculoskeletal pain on insomnia onset: a prospective cohort study. Rheumatology 2015;54:248-56.

34. Office for National Statistics. Standard occupational classification 2000, vol. 2. London: The Coding Index, 2000.

35. Bergner M, Bobbitt RA, Carter WB, et al. The sickness impact profile: development and final revision of a health status measure. Med Care 1981;19:787-805

36. VanderWeele TJ, Ding P. Sensitivity analysis in observational research: introducing the E-value. Ann Intern Med 2017;167:268-74.

37. Win S, Parakh K, Eze-Nliam CM, et al. Depressive symptoms, physical inactivity and risk of cardiovascular mortality in older adults: the cardiovascular health study. Heart 2011;97:500-5.

38. Simonsick EM, Guralnik JM, Volpato S, et al. Just get out the door! importance of walking outside the home for maintaining mobility: findings from the women's health and aging study. J Am Geriatr Soc 2005;53:198-203.

39. Machado MO, Veronese N, Sanches M, et al. The association of depression and all-cause and cause-specific mortality: an umbrella review of systematic reviews and meta-analyses. BMC Med 2018;16:112.

40. Harrold LR, Yood RA, Straus W, et al. Challenges of estimating health service utilization for osteoarthritis patients on a population level. J Rheumatol 2002;29:1931-6.

41. Kadhim-Saleh A, Green M, Williamson T, et al. Validation of the diagnostic algorithms for 5 chronic conditions in the Canadian primary care sentinel surveillance network (CPCSSN): a Kingston practice-based research network (PBRN) report. The Am Board Fam Med 2013;26:159-67.

42. Yu D, Jordan KP, Bedson J, et al. Population trends in the incidence and initial management of osteoarthritis: age-period-cohort analysis of the clinical practice research Datalink, 1992-2013. Rheumatology 2017;56:1902-17.

43. Merrill RM, Richardson JS. Validity of self-reported height, weight, and body mass index: findings from the National health and nutrition examination survey, 2001-2006. Prev Chronic Dis 2009;6.

44. Stommel M, Schoenborn CA. Accuracy and usefulness of BMI measures based on self-reported weight and height: findings from the NHANES \& NHIS 2001-2006. BMC Public Health 2009:9:421.

45. Altman DG, Royston P. The cost of dichotomising continuous variables. BMJ 2006;332.

46. Streiner DL. Breaking up is hard to do: the heartbreak of dichotomizing continuous data. Can J Psychiatry 2002;47:262-6.

47. Lapointe-Shaw L, Bouck Z, Howell NA, et al. Mediation analysis with a time-to-event outcome: a review of use and reporting in healthcare research. BMC Med Res Methodol 2018;18:118.

48. Bender R, Lange S. Adjusting for multiple testing - when and how? J Clin Epidemiol 2001;54:343-9. 